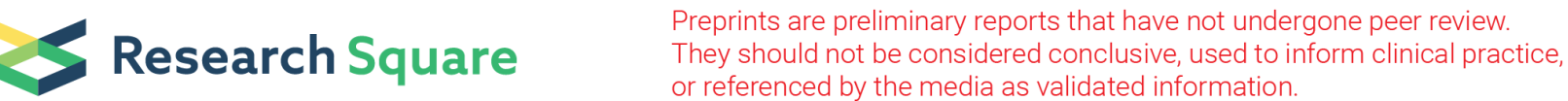

\section{Prevalence and Clinical Course of Upper Airway Respiratory Virus Infection in Critically III Patients with Hematologic Malignancies}

\author{
Jongmin Lee
}

Catholic University of Korea School of Medicine https://orcid.org/0000-0002-0165-5856

\section{Seok Chan Kim}

Catholic University of Korea School of Medicine

Chin Kook Rhee

Catholic University of Korea School of Medicine

Jaewoong Lee

Catholic University of Korea School of Medicine

Jong Wook Lee

Catholic University of Korea School of Medicine

Dong-Gun Lee ( $\nabla$ symonlee@catholic.ac.kr)

\section{Research}

Keywords: acute respiratory failure, upper respiratory tract, hematologic malignancy, mortality rate, respiratory virus, corticosteroids

Posted Date: May 29th, 2020

DOI: https://doi.org/10.21203/rs.3.rs-31868/v1

License: (c) (1) This work is licensed under a Creative Commons Attribution 4.0 International License. Read Full License

Version of Record: A version of this preprint was published at PLOS ONE on December 14th, 2021. See the published version at https://doi.org/10.1371/journal.pone.0260741. 


\section{Abstract}

Background The clinical significance of upper airway respiratory virus (RV) detection in patients with hematologic malignancies remains unclear. We aimed to investigate the association between upper airway RV detection and prognosis in critically ill patients with hematologic malignancies. Methods This retrospective observational study included 331 critically ill patients with hematologic malignancies who presented respiratory symptoms and their nasopharyngeal swab was tested using a multiplex PCR assay between January 2017 and December 2018. A logistic regression model was used to adjust for potential confounding factors in the association between assay positivity and in-hospital mortality. Results Among the 331 analyzed patients, RVs were detected in $29.0 \%$. The overall mortality rates in the intensive care unit and hospital were $56.8 \%$ and $65.9 \%$, respectively. Positive upper airway RV detection was associated with relapsed hematologic malignancies, higher level of C-reactive protein, and prior use of high dose steroids and anti-cancer chemotherapeutic drugs. Furthermore, it was independently associated with inhospital mortality (adjusted odds ratio, 2.36; 95\% confidence interval, 1.23 to 4.54). Among different RVs, parainfluenza virus was more prevalent among patients who died in the hospital than among those who survived $(11.5 \%$ vs. $3.5 \%, P=0.027)$. Conclusions $R V$ detection in the upper respiratory tract was relatively common in our cohort and was significantly associated with a poor prognosis. Thus, it can be used as a predictor of prognosis. Moreover, RV presence in the upper respiratory tract should be examined in patients who have previously been prescribed with high dose corticosteroids and anti-cancer drugs.

\section{Background}

Acute respiratory failure (ARF) is known as the most common and life-threatening reason for intensive care unit (ICU) admission in critically ill patients with hematologic malignancies [1, 2]. The causes of ARF are various, including pulmonary infections, complications of anti-cancer chemotherapy, or pulmonary involvement of the malignancies [3-5]. Despite using comprehensive diagnostic workup, the etiology of ARF remains undetermined in up to $25 \%$ of the cases $[3,6]$.

Respiratory viruses (RVs), including the influenza virus, parainfluenza virus (PIV), respiratory syncytial virus (RSV), adenovirus (ADV), bocavirus, human metapneumovirus (MPV), coronavirus, and human rhinoviruses (HRV), are detected in up to $20 \%$ of ARF episodes in critically ill patients with cancer [6, 7]. In immunocompetent patients, RVs generally cause self-limited upper respiratory tract infections (URTI). However, RVs are associated with poor prognosis in immunocompromised hosts [8-12]. Traditionally, viral culture has been considered the gold standard for diagnosing RV infection [13]. However, real-time PCR has replaced the role of viral culture. In particular, new multiplex PCR tests now enable the rapid detection of a wide spectrum of RVs $[14,15]$.

Although previous studies have reported that up to $40 \%$ of patients with hematologic malignancies have one or more viruses detected in their upper respiratory tract samples, RVs have been much less considered as the cause of ARF [16-18]. A positive RV PCR test on upper respiratory tract may indicate asymptomatic carriage; however, it may also reflect true upper or lower respiratory tract infection [17-19]. 
To date, the clinical significance of upper airway RV detection in patients with hematologic malignancies remains unclear. Thus, our objective was to investigate the clinical impact of positive PCR test for RV presence in the upper respiratory tract in critically ill patients with hematologic malignancies and pneumonia.

\section{Methods}

\section{Patients}

We retrospectively studied a cohort of critically ill patients with hematologic malignancies who were admitted to the medical and hematology ICUs of Seoul St. Mary's Hospital (Seoul, Korea) between January 2017 and December 2018. In this hospital, more than 500 hematopoietic stem cell transplantations (HSCTs) are performed annually. The study population included patients with hematologic malignancies and respiratory symptoms who underwent testing for RVs in upper respiratory tract samples within 24 hours after ICU admission. Patients with active hematologic malignancies were defined as those undergoing concurrent evaluation and treatment without a diagnosis of remission [20]. Patients were identified by medical record review. This study was approved by the institutional review board of Seoul St. Mary's Hospital (KC20RISI0297) and the requirement for informed consent was waived.

\section{Data collection}

Epidemiologic and clinical data were collected from the patients' medical charts at ICU admission. Data included sex; age; laboratory findings, including absolute neutrophil count (ANC), absolute lymphocyte count (ALC), high sensitivity C-reactive protein (hs-CRP), and procalcitonin level at ICU admission; characteristics of the hematologic malignancies, including the type of malignancy, current status, and prior treatments; presence of pneumonia at ICU admission; Sequential Organ Failure Assessment (SOFA) score at admission; use of corticosteroids, immunosuppressants, and anti-cancer chemotherapeutic drugs during the 30 days prior to ICU admission; use of mechanical ventilator; and the reason for ICU admission, including ARF, sepsis, and septic shock. Furthermore, comorbidity data were collected from the studied patients and used to calculate the Charlson comorbidity score index (CCI) [21].

Pneumonia was defined as the presence of a new infiltrate on a chest radiograph plus one or more of the following symptoms: fever (temperature $\geq 38.0^{\circ} \mathrm{C}$ ) or hypothermia (temperature $<35.0^{\circ} \mathrm{C}$ ), new cough with or without sputum production, pleuritic chest pain, dyspnea, and altered breath sounds on auscultation [22]. The doses of corticosteroids were expressed as the prednisolone-equivalent doses. Respiratory symptoms included cough, sputum, and breathlessness. ARF was defined as oxygen saturation $<90 \%$ or $\mathrm{PaO}_{2}<60 \mathrm{mmHg}$ on room air, combined with a respiratory rate $>30$ breaths $/ \mathrm{min}$ and/or clinical signs of respiratory distress $[1,23]$. Sepsis and septic shock diagnosis were retrospectively confirmed based on medical records and according to international consensus guidelines [24]. Patients 
with nosocomial RV infection were defined as those admitted to the hospital for a reason other than acute respiratory infection, in whom respiratory symptoms developed $\geq 72$ hours after admission, and in whom RV infection was confirmed using PCR [25]. Finally, we studied the clinical outcomes, including ICU and in-hospital mortality.

\section{Molecular assay for respiratory virus detection}

Critically ill patients with hematologic malignancies and respiratory symptoms were screened for RVs at the discretion of physicians within 24 hours of admission; the clinical indications for testing included symptoms of an URTI or lower respiratory tract infection. Specimens for diagnostic testing included nasal swabs and nasopharyngeal aspirates. The RV PCR multiplex panel (AdvanSure RV real-Time PCR Kit; LG Life Sciences, Seoul, Korea) was used to test for influenza A and B viruses, PIV, ADV, RSV, MPV, HRV, bocavirus, and coronavirus. Nucleic acid extraction was performed using the QIAamp DNA Mini Kit in an automated extractor (Qiacube, Qiagen, Hilden, Germany).

\section{Statistical analysis}

All results are reported as means \pm standard deviations for normally distributed continuous variables and as medians and interquartile ranges for non-normally distributed continuous data. Categorical data are described as numbers (\%). Patient characteristics were compared using the chi-squared test or Fisher's exact test, as appropriate, for categorical variables, and independent samples $t$-tests for continuous variables. Multivariate analysis was performed to investigate associations between patient characteristics and hospital mortality. Odds ratios (OR) and the corresponding $95 \%$ confidence interval (Cl) were computed. Goodness-of-fit was computed to assess the relevance of the logistic regression model. Probabilities of survival after ICU admission for each group were estimated using the KaplanMeier method and compared using the log rank test. All tests were two-sided, and $P$ values $<0.05$ were considered statistically significant. All statistical analyses were performed using $R 3.6 .1$ version ( $R$ Foundation, Vienna, Austria).

\section{Results}

Among the 806 patients with hematologic malignancies admitted to our medical and hematology ICUs from January 2017 to December 2018, 331 (41.1\%) had RV multiplex PCR test on their upper respiratory tract samples within 24 hours after ICU admission. Of these 331 patients, $96(29.0 \%)$ had one or more positive RV PCR result (Figure 1).

\section{Patient characteristics}


Table 1 shows the patients' baseline characteristics. Of the 331 analyzed patients, 195 (58.9\%) were men. The patients' median age was 57.0 years. Almost half of the patients had acute leukemia (50.2\%), 272 (82.2\%) patients had active hematologic malignancies, 63 (19.0\%) had relapsed diseases. and 104 (31.4\%) were allogenic HSCT recipients. Pneumonia was present in 272 patients (82.2\%) at ICU admission. ARF was present in 268 (81.0\%) patients, and sepsis or septic shock were present in 272 (82.2\%) patients. High flow nasal cannula was applied to 139 (42.0\%) patients, and invasive mechanical ventilation was provided to $212(64.1 \%)$ patients. Moreover, $101(30.5 \%)$ patients received renal replacement therapy (RRT), while only $2(0.6 \%)$ patients received extracorporeal membrane oxygenation therapy. The median SOFA score at ICU admission and the median CCI score were $9.0(6.0-12.0)$ and $3.0(2.0-5.0)$, respectively. 
Table 1

Baseline characteristics of patients

\begin{tabular}{ll} 
Variable & No. of patien \\
Age, yr & $195(58.9)$ \\
Underlying malignancies & $57.0(44.0$ \\
\hline Acute myeloid leukemia & \\
\hline Acute lymphoblastic leukemia & $118(35.6)$ \\
Chronic myeloid leukemia & $48(14.5)$ \\
\hline Multiple myeloma & $12(3.6)$ \\
\hline Myelodysplastic syndrome & $53(16.0)$ \\
Lymphoma & $22(6.6)$ \\
\hline Others ${ }^{\star}$ & $61(18.4)$
\end{tabular}

Malignancy state at ICU admission

Active disease

$272(82.2)$

Relapsed

$63(19.0)$

Complete remission

$59(17.8)$

HSCT recipients

109 (32.9)

Autologous HSCT

$19(5.7)$

Allogenic HSCT

104 (31.4)

Chronic respiratory insufficiency

35 (10.6)

Presence of pneumonia at ICU admission

$272(82.2)$

Reasons for ICU admission

Acute respiratory failure

$268(81.0)$

Sepsis/Septic shock

$272(82.2)$

Life-supporting interventions

High flow nasal cannula

$139(42.0)$

Mechanical ventilation

$212(64.0)$

Renal replacement therapy

$101(30.5)$

Extracorporeal membrane oxygenation

$2(0.6)$ 
No., number; IQR, interquartile range; HSCT, hematopoietic stem cell transplant; ICU, intensive care unit; SOFA, sequential organ failure assessment score

*Others include primary myelofibrosis (5), hemophagocytic lymphohistiocytosis (1), Castleman disease (2), aplastic anemia (1), essential thrombocytosis (1), Waldenstrom macroglobulinemia (1), plasma cell leukemia (1), chronic lymphocytic leukemia (4), chronic eosinophilic leukemia (1).

Figure 2 shows the distribution of patients according to the RV detected in upper respiratory tract samples by multiplex PCR. Overall, the most prevalent virus was PIV $(30.2 \%, 29$ of 96 patients with positive results), followed by HRV $(22.9 \%, 22$ of 96$)$, RSV $(14.6 \%, 14$ of 96$)$, coronavirus $(13.5 \%, 13$ of 96$)$, influenza A and B viruses (8.3\%, 8 of 96$)$, MPV (7.3\%, 7 of 96$)$, ADV (5.2\%, 5 of 96$)$, and bocavirus $(1.0 \%, 1$ of 96 ). Only $3.1 \%$ of the patients ( 3 of 96 ) with positive RV PCR results had coinfections by two or more viruses. Additional Table 1 and Figure 3 show the seasonal distribution of RV cases for each type of virus. Influenza viruses and RSV were significantly more predominant in winter $(P<0.001$ for influenza, $P$ $=0.031$ for RSV), while PIV was more frequent during summer and autumn $(P=0.009)$. Table 2 shows the comparison of the percentages of patients with positive multiplex PCR results for RVs in general and for each respiratory pathogen according to presence of ARF and in-hospital mortality. Overall, RVs were more prevalent in patients with than without ARF $(31.7 \%$ vs. $17.5 \%, P=0.037)$ and in patients who died in the hospital than in those who survived $(34.4 \%$ vs. $18.6 \%, P=0.004)$. Among RVs, particularly PIV was more frequently detected in patients who died in the hospital than in survivors $(11.5 \% \mathrm{vs} .3 .5 \%, P=$ 0.027). 
Table 2

Comparison of upper airway RV PCR according to presence of acute respiratory failure and in-hospital mortality

\begin{tabular}{|c|c|c|c|c|c|c|}
\hline Variable & $\begin{array}{l}\text { Patients } \\
\text { without ARF } \\
(n=63)\end{array}$ & $\begin{array}{l}\text { Patients } \\
\text { with ARF } \\
(n=268)\end{array}$ & $\begin{array}{l}P \\
\text { value }\end{array}$ & $\begin{array}{l}\text { Survivors } \\
(\mathrm{n}=113)\end{array}$ & $\begin{array}{l}\text { Patients } \\
\text { who died } \\
(n=218)\end{array}$ & $\begin{array}{l}P \\
\text { value }\end{array}$ \\
\hline $\begin{array}{l}\text { Positive upper airway } \\
\text { RV PCR }\end{array}$ & $11(17.5)$ & 85 (31.7) & 0.037 & 21 (18.6) & 75 (34.4) & 0.004 \\
\hline Influenza A \& B & $0(0.0)$ & $8(3.0)$ & 0.351 & $3(2.7)$ & $5(2.3)$ & 1.000 \\
\hline $\begin{array}{l}\text { Respiratory syncytial } \\
\text { virus }\end{array}$ & $3(4.8)$ & $11(4.1)$ & 1.000 & $3(2.7)$ & $11(5.0)$ & 0.461 \\
\hline Parainfluenza & $3(4.8)$ & $26(9.7)$ & 0.317 & $4(3.5)$ & 25 (11.5) & 0.027 \\
\hline Rhinovirus & $2(3.2)$ & $20(7.5)$ & 0.343 & $9(8.0)$ & $13(6.0)$ & 0.645 \\
\hline Metapneumovirus & $1(1.6)$ & $6(2.2)$ & 1.000 & $1(0.9)$ & $6(2.8)$ & 0.473 \\
\hline Adenovirus & $1(1.6)$ & $4(1.5)$ & 1.000 & $0(0.0)$ & $5(2.3)$ & 0.251 \\
\hline Coronavirus & $1(1.6)$ & $12(4.5)$ & 0.482 & $4(3.5)$ & $9(4.1)$ & 1.000 \\
\hline Bocavirus & $1(1.6)$ & $0(0.0)$ & 0.430 & $0(0.0)$ & $1(0.5)$ & 1.000 \\
\hline
\end{tabular}

\section{Characteristics and outcomes in patients with and without upper airway respiratory virus infection}

Table 3 shows a comparison of the characteristics and outcomes between patients with positive and those with negative results in RV assay. The percentage of patients with relapsed hematologic malignancies was higher among patients with positive RV results than those with negative $(30.2 \% \mathrm{vs}$. $14.5 \%, P=0.002)$. The median level of hs-CRP was significantly higher in patients with positive than with negative RV PCR results (16.2 vs. 11.2, $P=0.027)$, but there was no difference in the level of procalcitonin between the two groups. The proportion of patients with ARF was significantly higher in patients with positive than with negative RV PCR results $(88.5 \%$ vs. $77.9 \%, P=0.037)$. The proportion of patients with sepsis or septic shock was not significantly different between the two groups. Moreover, the proportion of patients who used corticosteroids or anti-cancer chemotherapeutic drugs within 30 days prior to ICU admission was higher among patients with than those without upper airway RVs (corticosteroids: $87.5 \%$ vs. $63.8 \%, P<0.001$; chemotherapy: $68.8 \%$ vs. $55.7 \%, P=0.039$ ). Invasive mechanical ventilation was used significantly more often in RV-positive than RV-negative patients $(74.0 \%$ vs. $60.0 \%, P=0.023)$. ICU and in-hospital mortality rates were significantly higher in RV-positive than RV-negative patients (ICU: $68.8 \%$ vs. $51.9 \%, P=0.007$; hospital, $78.1 \%$ vs. $60.9 \%, P=0.004)$. The probability of survival was 
significantly lower for patients positive for upper airway tract RV than those negative $(P=0.011$, log-rank test; Figure 4) 
Table 3

Comparison of clinical characteristics of patients with negative and positive upper airway respiratory virus PCR

\begin{tabular}{|c|c|c|c|}
\hline Variable & $\begin{array}{l}\text { Negative RV } \\
\text { PCR } \\
(n=235)\end{array}$ & $\begin{array}{l}\text { Positive RV PCR } \\
(\mathrm{n}=96)\end{array}$ & $\begin{array}{l}P \\
\text { value }\end{array}$ \\
\hline Age, years & $\begin{array}{l}58.0(44.0- \\
67.5)\end{array}$ & $\begin{array}{l}55.0(43.5- \\
64.0)\end{array}$ & 0.360 \\
\hline Sex, male & $134(57.0)$ & $61(63.5)$ & 0.332 \\
\hline \multicolumn{4}{|l|}{ Underlying hematologic malignancies } \\
\hline Acute myeloid leukemia & $93(39.6)$ & $25(26.0)$ & \multirow[t]{7}{*}{0.068} \\
\hline Acute lymphoblastic leukemia & $32(13.6)$ & $15(15.6)$ & \\
\hline Chronic myeloid leukemia & $11(4.7)$ & $1(1.0)$ & \\
\hline Multiple myeloma & $31(13.2)$ & $22(22.9)$ & \\
\hline Myelodysplastic syndromes & $16(6.8)$ & $6(6.2)$ & \\
\hline Lymphoma & $39(16.6)$ & $22(22.9)$ & \\
\hline Others & $13(5.5)$ & $5(5.2)$ & \\
\hline \multicolumn{4}{|l|}{ HSCT recipients } \\
\hline Autologous HSCT & $11(4.7)$ & $8(8.3)$ & 0.300 \\
\hline Allogenic HSCT & $68(28.9)$ & $36(37.5)$ & 0.164 \\
\hline \multicolumn{4}{|l|}{ Disease status } \\
\hline Active & $192(81.7)$ & $80(83.3)$ & 0.846 \\
\hline Relapsed & $34(14.5)$ & $29(30.2)$ & 0.002 \\
\hline SOFA score & $9.0(6.0-12.0)$ & $\begin{array}{l}10.0(6.5- \\
13.0)\end{array}$ & 0.135 \\
\hline Charlson Comorbidity Index & $3.0(2.0-5.0)$ & $3.0(2.0-4.0)$ & 0.165 \\
\hline Presence of pneumonia on ICU admission & $188(80.0)$ & $84(87.5)$ & 0.144 \\
\hline \multicolumn{4}{|l|}{ Laboratory findings on ICU admission } \\
\hline Absolute neutrophil count, $10^{9} / \mathrm{L}$ & $3.7(0.1-7.4)$ & $2.4(0.2-6.8)$ & 0.697 \\
\hline Absolute lymphocyte count, $10^{9} / \mathrm{L}$ & $0.7(0.2-1.7)$ & $0.5(0.1-1.3)$ & 0.071 \\
\hline High sensitivity C-reactive protein, $\mathrm{mg} / \mathrm{dL}$ & $11.2(5.4-$ & $16.2(9.3-$ & 0.027 \\
\hline
\end{tabular}




\begin{tabular}{|c|c|c|c|}
\hline & 22.1) & 23.5) & \\
\hline Procalcitonin, $\mathrm{ng} / \mathrm{mL}$ & $1.7(0.3-10.6)$ & $1.9(0.9-5.0)$ & 0.428 \\
\hline \multicolumn{3}{|l|}{ Season at ICU admission } & \multirow[t]{5}{*}{0.419} \\
\hline Spring & $62(26.4)$ & $19(19.8)$ & \\
\hline Summer & $62(26.4)$ & $29(30.2)$ & \\
\hline Fall & $61(26.0)$ & $22(22.9)$ & \\
\hline Winter & $50(21.3)$ & $26(27.1)$ & \\
\hline \multicolumn{4}{|l|}{ Reasons for ICU admission } \\
\hline Acute respiratory failure & $183(77.9)$ & $85(88.5)$ & 0.037 \\
\hline Sepsis/Septic shock & $194(82.6)$ & $78(81.2)$ & 0.902 \\
\hline \multicolumn{4}{|l|}{$\begin{array}{l}\text { Use of medications within } 30 \text { days prior to ICU } \\
\text { admission }\end{array}$} \\
\hline Use of corticosteroids & $150(63.8)$ & $84(87.5)$ & $<0.001$ \\
\hline Accumulative prednisolone-equivalent dose, $\mathrm{mg} / \mathrm{kg}$ & $5.4(0.0-15.4)$ & $\begin{array}{l}11.8(4.2- \\
21.8)\end{array}$ & $<0.001$ \\
\hline Use of immunosuppressants & $48(20.4)$ & $28(29.2)$ & 0.116 \\
\hline Use of anti-cancer chemotherapeutic drugs & $131(55.7)$ & $66(68.8)$ & 0.039 \\
\hline \multicolumn{4}{|l|}{ Life-supporting interventions } \\
\hline High flow nasal cannula & $97(41.3)$ & $42(43.8)$ & 0.771 \\
\hline Mechanical ventilation & $141(60.0)$ & $71(74.0)$ & 0.023 \\
\hline Renal replacement therapy & $73(31.1)$ & $28(29.2)$ & 0.835 \\
\hline Extracorporeal membrane oxygenation & $0(0.0)$ & $2(2.1)$ & 0.150 \\
\hline \multicolumn{4}{|l|}{ Prognosis of patients } \\
\hline ICU mortality & $122(51.9)$ & $66(68.8)$ & 0.007 \\
\hline In-hospital mortality & $143(60.9)$ & $75(78.1)$ & 0.004 \\
\hline \multicolumn{4}{|c|}{ Data are presented as number (percentage) or as median (interquartile range) } \\
\hline $\begin{array}{l}P C R \text {, polymerase chain reaction; } H S C T \text {, hematopoiet } \\
\text { failure assessment score; ICU, intensive care unit }\end{array}$ & tem cell transpl & SOFA, sequenti & rgan \\
\hline
\end{tabular}




\section{Factors associated with positive upper airway respiratory virus detection among recipients of allogenic hematopoietic stem cell transplants}

Table 4 shows a comparison of the characteristics and outcomes between patients with positive and those with negative RV PCR results among recipients and non-recipients of allogeneic HSCT. ALC was significantly lower in patients with positive than with negative upper airway RV results among allogeneic HSCT recipients $\left(0.4\right.$ [0.2 - 1.1] vs. 0.9 [0.3 - 1.8] cells $\left.\times 10^{9} / \mathrm{L}, P=0.028\right)$. In both groups, steroid use within 30 days prior to ICU admission was significantly greater for RV-positive than RV-negative patients (allogeneic HSCT recipients: $94.4 \%$ vs. $72.1 \%, P=0.014$; non-recipients: $83.3 \%$ vs. $60.5 \%, P=0.002$ ). The doses of corticosteroids were also significantly greater among those with positive than those with negative RV PCR results (allogeneic HSCT recipients, 12.8 [5.3 - 23.8] vs. $6.9[0.2-18.9] \mathrm{mg} / \mathrm{kg}$ prednisolone-equivalent dose, $P=0.026$; non-recipients, $8.2[2.0-19.1] \mathrm{vs} .5 .3[0.0-13.9] \mathrm{mg} / \mathrm{kg}$ prednisolone-equivalent dose, $P=0.010)$. In the allogeneic HSCT recipients' group, in-hospital mortality rate was significantly higher among those with positive than with negative RV PCR results $(83.3 \% \mathrm{vs}$. $61.8 \%, P=0.041)$. Although ICU and in-hospital mortality rates were also higher among those with positive than with negative RV PCR results among non-HSCT recipients, the results were not statistically significant. Additional Table 2 shows the comparison of patients' distribution depending on positive multiplex PCR results for RVs in general and for each respiratory pathogen detected in upper respiratory tract samples between recipients and non-recipients of allogeneic HSCT. Among allogeneic HSCT recipients, PIV was the most common RV and significantly more prevalent than among non-recipients (15.4\% vs. $5.7 \%, P=0.007$ ) 
Table 4

Comparison of the clinical characteristics of allogenic hematopoietic stem cell transplant recipients and non-recipients with or without positive upper airway respiratory virus PCR.

\begin{tabular}{|c|c|c|c|c|c|c|}
\hline \multirow[t]{3}{*}{ Variable } & \multicolumn{3}{|c|}{ Patients with allogenic HSCT } & \multicolumn{3}{|c|}{$\begin{array}{l}\text { Patients without allogenic } \\
\text { HSCT }\end{array}$} \\
\hline & $\begin{array}{l}\text { Negative } \\
\text { RVPCR }\end{array}$ & $\begin{array}{l}\text { Positive } \\
\text { RV PCR }\end{array}$ & $\begin{array}{l}P \\
\text { value }\end{array}$ & $\begin{array}{l}\text { Negative } \\
\text { RV PCR }\end{array}$ & $\begin{array}{l}\text { Positive } \\
\text { RV PCR }\end{array}$ & $\begin{array}{l}P \\
\text { value }\end{array}$ \\
\hline & $(n=68)$ & $(n=36)$ & & $\begin{array}{l}(n= \\
167)\end{array}$ & $(n=60)$ & \\
\hline Age & $\begin{array}{l}48.5 \\
(40.5- \\
58.5)\end{array}$ & $\begin{array}{l}50.0 \\
(38.5- \\
61.0)\end{array}$ & 0.715 & $\begin{array}{l}59(48.0 \\
-70.0)\end{array}$ & $\begin{array}{l}57.0 \\
(46.5- \\
67.5)\end{array}$ & 0.354 \\
\hline Sex, Male & $37(54.4)$ & $24(66.7)$ & 0.318 & $\begin{array}{l}97 \\
(58.1)\end{array}$ & $\begin{array}{l}37 \\
(61.7)\end{array}$ & 0.741 \\
\hline \multicolumn{7}{|l|}{ Disease status } \\
\hline Active & $52(76.5)$ & $23(63.9)$ & 0.258 & $\begin{array}{l}75 \\
(44.9)\end{array}$ & $\begin{array}{l}17 \\
(28.3)\end{array}$ & 0.037 \\
\hline Relapsed & $32(47.1)$ & $21(58.3)$ & 0.375 & $\begin{array}{l}160 \\
(95.8)\end{array}$ & $\begin{array}{l}59 \\
(98.3)\end{array}$ & 0.616 \\
\hline SOFA score & $\begin{array}{l}7.0(5.0- \\
9.5)\end{array}$ & $\begin{array}{l}9.0(6.5- \\
12.0)\end{array}$ & 0.102 & $\begin{array}{l}10.0(6.5 \\
-13.0)\end{array}$ & $\begin{array}{l}11.0(6.5 \\
-13.0)\end{array}$ & 0.285 \\
\hline Charlson Comorbidity Index & $\begin{array}{l}3.0(2.0- \\
4.0)\end{array}$ & $\begin{array}{l}3.0(2.0- \\
4.0)\end{array}$ & 0.729 & $\begin{array}{l}3.0(2.0 \\
-5.0)\end{array}$ & $\begin{array}{l}3.0(2.0 \\
-5.0)\end{array}$ & 0.262 \\
\hline $\begin{array}{l}\text { Presence of pneumonia on ICU } \\
\text { admission }\end{array}$ & $54(79.4)$ & $29(80.6)$ & 1.000 & $\begin{array}{l}134 \\
(80.2)\end{array}$ & $\begin{array}{l}55 \\
(91.7)\end{array}$ & 0.067 \\
\hline \multicolumn{7}{|l|}{$\begin{array}{l}\text { Laboratory findings on ICU } \\
\text { admission }\end{array}$} \\
\hline $\begin{array}{l}\text { Absolute neutrophil count, } \times \\
10^{9} / \mathrm{L}\end{array}$ & $\begin{array}{l}5.3(1.0- \\
9.5)\end{array}$ & $\begin{array}{l}3.5(0.3- \\
7.2)\end{array}$ & 0.258 & $\begin{array}{l}2.5(0.1 \\
-6.5)\end{array}$ & $\begin{array}{l}1.9(0.2 \\
-5.7)\end{array}$ & 0.981 \\
\hline $\begin{array}{l}\text { Absolute lymphocyte count, } \times \\
10^{9} / \mathrm{L}\end{array}$ & $\begin{array}{l}0.9(0.3- \\
1.8)\end{array}$ & $\begin{array}{l}0.4(0.2- \\
1.1)\end{array}$ & 0.028 & $\begin{array}{l}0.6(0.2 \\
-1.7)\end{array}$ & $\begin{array}{l}0.5(0.1 \\
-1.7)\end{array}$ & 0.438 \\
\hline Procalcitonin, ng/mL & $\begin{array}{l}1.0(0.3- \\
7.8)\end{array}$ & $\begin{array}{l}1.7(0.4- \\
7.5)\end{array}$ & 0.461 & $\begin{array}{l}2.4(0.3 \\
-12.2)\end{array}$ & $\begin{array}{l}2.0(0.9 \\
-5.0)\end{array}$ & 0.622 \\
\hline $\begin{array}{l}\text { High sensitivity C-reactive } \\
\text { protein, } \mathrm{mg} / \mathrm{dL}\end{array}$ & $\begin{array}{l}7.7(2.9- \\
17.2)\end{array}$ & $\begin{array}{l}13.3(5.2 \\
-17.7)\end{array}$ & 0.150 & $\begin{array}{l}12.9(6.6 \\
-24.6)\end{array}$ & $\begin{array}{l}19.5 \\
(11.7- \\
25.1)\end{array}$ & 0.032 \\
\hline \multicolumn{7}{|l|}{ Reasons for ICU admission } \\
\hline Acute respiratory failure & $54(79.4)$ & $30(83.3)$ & 0.825 & $\begin{array}{l}129 \\
(77.2)\end{array}$ & $\begin{array}{l}55 \\
(91.7)\end{array}$ & 0.024 \\
\hline
\end{tabular}


Sepsis/Septic shock

$46(67.6) \quad 26(72.2) \quad 0.683$

131

44

(78.4)

(73.3)

0.530

Use of medications within 30

days prior to ICU admission

\begin{tabular}{|c|c|c|c|c|c|c|}
\hline Use of corticosteroids & $49(72.1)$ & $34(94.4)$ & 0.014 & $\begin{array}{l}101 \\
(60.5)\end{array}$ & $\begin{array}{l}50 \\
(83.3)\end{array}$ & 0.002 \\
\hline $\begin{array}{l}\text { Accumulative prednisolone- } \\
\text { equivalent dose, } \mathrm{mg} / \mathrm{kg}\end{array}$ & $\begin{array}{l}6.9(0.2- \\
18.9)\end{array}$ & $\begin{array}{l}12.8(5.3 \\
-23.8)\end{array}$ & 0.026 & $\begin{array}{l}5.3(0.0 \\
-13.9)\end{array}$ & $\begin{array}{l}8.2(2.0 \\
-19.1)\end{array}$ & 0.010 \\
\hline $\begin{array}{l}\text { Use of immunomodulatory } \\
\text { drugs }\end{array}$ & $45(66.2)$ & $26(72.2)$ & 0.683 & $3(1.8)$ & $2(3.3)$ & 0.855 \\
\hline Use of chemotherapeutic drugs & $27(39.7)$ & $16(44.4)$ & 0.797 & $\begin{array}{l}104 \\
(62.3)\end{array}$ & $\begin{array}{l}50 \\
(83.3)\end{array}$ & 0.005 \\
\hline
\end{tabular}

Life-supporting interventions

High flow nasal cannula

$30(44.1) \quad 20(55.6) \quad 0.366$

67

(40.1)

22

(36.7)

0.752

Mechanical ventilation

$45(66.2) \quad 28(77.8) \quad 0.315 \quad 96$

(57.5)

43

(71.7)

0.075

Renal replacement therapy

$19(27.9)$

$11(30.6)$

0.958

54

(32.3)

17

(28.3)

0.681

Prognosis of patients

ICU mortality

$36(52.9) \quad 26(72.2) \quad 0.090 \quad 86$

(51.5)

40

(66.7)

In-hospital mortality

$42(61.8)$

30 (83.3)

0.041

101

(60.5)

45

(75.0)

$45 \quad 0.063$

Data are presented as number (percentage) or as median (interquartile range)

HSCT, hematopoietic stem cell transplant; PCR, polymerase chain reaction; SOFA, sequential organ failure assessment score; ICU, intensive care unit

\section{Factors associated with increased hospital mortality}

Univariate comparisons of the clinical characteristics of patients who survived and those who died are presented in Table 5. Relapsed hematologic malignancies were more likely among non-survivors than among survivors $(24.3 \%$ vs. $8.8 \%, P=0.001)$. Among non-survivors, a higher proportion of patients had positive upper airway RV PCR results (34.4\% vs. $18.6 \%, P=0.004)$, pneumonia on ICU admission (91.7\% vs. $63.7 \%, P<0.001)$, invasive pulmonary aspergillosis $(14.2 \%$ vs. $6.2 \%, P=0.047)$, ARF $(85.3 \%$ vs. $72.6 \%$, $P=0.008)$, and sepsis or septic shock ( $82.1 \% v s .60 .2 \%, P<0.001)$ than the respective proportions of patients among survivors. Moreover, non-survivors had a higher SOFA score (11.0 [8.0 - 13.0] vs. 7.0 [4.0 - 9.0], $P<0.001)$, lower ANC (2.2 [0.0 - 6.8] vs. $4.5[0.5-7.9]$ cells $\left.\times 10^{9} / L, P=0.009\right)$, and higher hs-CRP 
$(14.9[7.7-24.4] v s .8 .8[2.8-19.3] \mathrm{mg} / \mathrm{dL}, P<0.001)$ than survivors, while more patients among nonsurvivors than among survivors required mechanical ventilation $(81.7 \%$ vs. $30.1 \%, P<0.001)$ and RRT (37.6\% vs. $16.8 \%, P<0.001)$. Upper respiratory tract RV PCR positivity was independently associated with in-hospital mortality on multivariate analysis after adjusting for potential confounding factors (adjusted OR 2.36, 95\% Cl 1.23 - 4.54, $P=0.010$; Table 6). Other independent risk factors for in-hospital mortality included relapsed hematologic malignancy (adjusted OR 2.63, 95\% $\mathrm{Cl} 1.16-6.00, P=0.021$ ), presence of pneumonia on ICU admission (adjusted OR 4.63, 95\% Cl $2.19-9.81, P<0.001$ ), requirement of RRT (adjusted OR 2.85, 95\% Cl $1.48-5.49, P=0.002$ ), and the presence of sepsis or septic shock on ICU admission (adjusted OR 2.33, 95\% Cl $1.24-4.36, P=0.008$ ). 
Table 5

Comparison of the clinical characteristics of hospital survivors and non-survivors

\begin{tabular}{|c|c|c|c|}
\hline Variable & $\begin{array}{l}\text { Survived } \\
\text { patients } \\
(n=113)\end{array}$ & $\begin{array}{l}\text { Died patients } \\
(\mathrm{n}=218)\end{array}$ & $\begin{array}{l}P \\
\text { value }\end{array}$ \\
\hline Age & $\begin{array}{l}54.0(41.0- \\
66.0)\end{array}$ & $\begin{array}{l}58.0(46.0- \\
67.0)\end{array}$ & 0.099 \\
\hline Sex, Male & $66(58.4)$ & $129(59.2)$ & 0.987 \\
\hline \multicolumn{4}{|l|}{ Underlying hematologic malignancies } \\
\hline Acute myeloid leukemia & $40(35.4)$ & $78(35.8)$ & \multirow[t]{7}{*}{0.072} \\
\hline Acute lymphoblastic leukemia & $17(15.0)$ & $30(13.8)$ & \\
\hline Chronic myeloid leukemia & $5(4.4)$ & $7(3.2)$ & \\
\hline Multiple myeloma & $21(18.6)$ & $32(14.7)$ & \\
\hline Myelodysplastic syndromes & $5(4.4)$ & $17(7.8)$ & \\
\hline Lymphoma & $14(12.4)$ & $47(21.6)$ & \\
\hline Others & $11(9.7)$ & $7(3.2)$ & \\
\hline Allogenic HSCT recipients & $32(28.3)$ & $72(33.0)$ & 0.453 \\
\hline \multicolumn{4}{|l|}{ Disease status } \\
\hline Active & $27(23.9)$ & $32(14.7)$ & 0.054 \\
\hline Relapsed & $10(8.8)$ & $53(24.3)$ & 0.001 \\
\hline Positive upper airway RV PCR & $21(18.6)$ & $75(34.4)$ & 0.004 \\
\hline SOFA score on ICU admission & $7.0(4.0-9.0)$ & $11.0(8.0-13.0)$ & $<0.001$ \\
\hline Charlson Comorbidity Index & $3.0(2.0-4.0)$ & $3.0(2.0-5.0)$ & 0.101 \\
\hline Presence of pneumonia on ICU admission & $72(63.7)$ & $200(91.7)$ & $<0.001$ \\
\hline Invasive pulmonary aspergillosis & $7(6.2)$ & $31(14.2)$ & 0.047 \\
\hline \multicolumn{4}{|l|}{ Laboratory findings on ICU admission } \\
\hline Absolute neutrophil count, $\times 10^{9} / \mathrm{L}$ & $4.5(0.5-7.9)$ & $2.2(0.0-6.8)$ & 0.009 \\
\hline Absolute lymphocyte count, $\times 10^{9} / \mathrm{L}$ & $0.7(0.3-1.6)$ & $0.6(0.1-1.8)$ & 0.492 \\
\hline Procalcitonin, $\mathrm{ng} / \mathrm{mL}$ & $1.4(0.2-11.4)$ & $2.0(0.6-8.6)$ & 0.406 \\
\hline High sensitivity C-reactive protein, $\mathrm{mg} / \mathrm{dL}$ & $8.8(2.8-19.3)$ & $14.9(7.7-24.4)$ & $<0.001$ \\
\hline
\end{tabular}




\begin{tabular}{|llll|}
\hline \multicolumn{1}{|l}{ Acute respiratory failure } & $82(72.6)$ & $186(85.3)$ & 0.008 \\
\hline Sepsis/Septic shock & $68(60.2)$ & $179(82.1)$ & $<0.001$ \\
\hline Life-supporting interventions & & & \\
\hline High flow nasal cannula & $41(36.3)$ & $98(45.0)$ & 0.162 \\
\hline Mechanical ventilation & $34(30.1)$ & $178(81.7)$ & $<0.001$ \\
\hline Renal replacement therapy & $19(16.8)$ & $82(37.6)$ & $<0.001$ \\
\hline $\begin{array}{l}\text { Extracorporeal membrane oxygenation } \\
\text { Use of medications in 30 days prior to ICU }\end{array}$ & $0(0.0)$ & $2(0.9)$ & 0.785 \\
\hline $\begin{array}{l}\text { admission } \\
\text { Use of corticosteroids }\end{array}$ & $79(69.9)$ & $155(71.1)$ & 0.922 \\
\hline $\begin{array}{l}\text { Accumulative prednisolone-equivalent dose, } \\
\text { mg/kg }\end{array}$ & $5.7(0.0-14.5)$ & $7.4(0.0-18.7)$ & 0.513 \\
\hline $\begin{array}{l}\text { Use of immunomodulatory drugs } \\
\text { Use of chemotherapeutic drugs }\end{array}$ & $60(20.4)$ & $53(24.3)$ & 0.500 \\
\hline $\begin{array}{l}\text { Data are presented as number (percentage) or as median (interquartile range) } \\
\text { HSCT, hematopoietic stem cell transplantation; RV, respiratory virus; PCR, polymerase chain reaction; } \\
\text { SOFA, sequential organ failure assessment score; ICU, intensive care unit }\end{array}$ & 0.111 \\
\hline
\end{tabular}


Table 6

Clinical factors affecting hospital mortality

\begin{tabular}{|c|c|c|c|c|c|c|}
\hline \multirow[t]{2}{*}{ Variable } & \multicolumn{3}{|c|}{ Univariable } & \multicolumn{3}{|c|}{ Multivariable } \\
\hline & $\begin{array}{l}\text { Crude } \\
\text { OR }\end{array}$ & $95 \% \mathrm{Cl}$ & $\begin{array}{l}P \\
\text { value }\end{array}$ & $\begin{array}{l}\text { Adjusted } \\
\text { OR }\end{array}$ & $95 \% \mathrm{Cl}$ & $\begin{array}{l}P \\
\text { value }\end{array}$ \\
\hline Positive upper airway RV PCR & 2.30 & $\begin{array}{l}1.33- \\
3.98\end{array}$ & 0.003 & 2.36 & $\begin{array}{l}1.23- \\
4.54\end{array}$ & 0.010 \\
\hline $\begin{array}{l}\text { Relapsed hematologic } \\
\text { malignancy }\end{array}$ & 3.31 & $\begin{array}{l}1.61- \\
6.79\end{array}$ & 0.001 & 2.63 & $\begin{array}{l}1.16- \\
6.00\end{array}$ & 0.021 \\
\hline $\begin{array}{l}\text { Presence of pneumonia on ICU } \\
\text { admission }\end{array}$ & 6.33 & $\begin{array}{l}3.42- \\
11.72\end{array}$ & $<0.001$ & 4.63 & $\begin{array}{l}2.19- \\
9.81\end{array}$ & $<0.001$ \\
\hline Invasive pulmonary aspergillosis & 2.51 & $\begin{array}{l}1.07- \\
5.90\end{array}$ & 0.035 & 1.52 & $\begin{array}{l}0.57- \\
4.09\end{array}$ & 0.406 \\
\hline High sensitivity C-reactive protein & 1.04 & $\begin{array}{l}1.01- \\
1.06\end{array}$ & 0.002 & 1.02 & $\begin{array}{l}0.99- \\
1.05\end{array}$ & 0.116 \\
\hline $\begin{array}{l}\text { Absolute neutrophil count on ICU } \\
\text { admission }\end{array}$ & 0.99 & $\begin{array}{l}0.96- \\
1.02\end{array}$ & 0.502 & 0.99 & $\begin{array}{l}0.95- \\
1.03\end{array}$ & 0.638 \\
\hline Renal replacement therapy & 2.98 & $\begin{array}{l}1.70- \\
5.24\end{array}$ & $<.001$ & 2.85 & $\begin{array}{l}1.48- \\
5.49\end{array}$ & 0.002 \\
\hline Acute respiratory failure & 2.20 & $\begin{array}{l}1.26- \\
3.84\end{array}$ & 0.006 & 1.17 & $\begin{array}{l}0.59- \\
2.31\end{array}$ & 0.661 \\
\hline $\begin{array}{l}\text { Sepsis/Septic shock on ICU } \\
\text { admission }\end{array}$ & 3.04 & $\begin{array}{l}1.82- \\
5.07\end{array}$ & $<.001$ & 2.33 & $\begin{array}{l}1.24- \\
4.36\end{array}$ & 0.008 \\
\hline
\end{tabular}

Table 7 shows the comparison of demographic and clinical characteristics between survivors and nonsurvivors among patients with positive upper respiratory tract RV PCR results. Notably, non-survivors were significantly older and had higher SOFA and CCI scores. A significantly larger proportion of patients had pneumonia at ICU admission ( $92.0 \%$ vs. $71.4 \%, P=0.032)$ and required mechanical ventilation during ICU stay among non-survivors, compared to the respective proportions among survivors $(86.7 \%$ vs. $28.6 \%, P<$ 0.001). The use of immunosuppressants, corticosteroids, and anti-cancer chemotherapeutic agents was not associated with mortality in patients with positive RV PCR results. After adjusting for potential confounding factors, in-hospital mortality remained significantly associated with the SOFA score (adjusted OR 1.20, 95\% Cl $1.11-1.31, P<0.001$ ), the presence of pneumonia at ICU admission (adjusted OR $4.90,95 \% \mathrm{Cl} 2.33-10.29, P<0.001$ ), and the use of mechanical ventilation during ICU stay (adjusted OR $6.86,95 \% \mathrm{Cl} 3.81-12.36, P<0.001$ ) among patients with positive RV PCR results (Table 8 ). 
Table 7

Comparison of the clinical characteristics of hospital survivors and non-survivors in patients with positive upper airway respiratory virus PCR.

\begin{tabular}{|c|c|c|c|}
\hline Variable & $\begin{array}{l}\text { Survived } \\
\text { patients } \\
(n=21)\end{array}$ & $\begin{array}{l}\text { Died patients } \\
(\mathrm{n}=75)\end{array}$ & $\begin{array}{l}P \\
\text { value }\end{array}$ \\
\hline Age & $45.6 \pm 16.8$ & $55.7 \pm 14.2$ & 0.007 \\
\hline Sex, Male & $16(76.2)$ & $45(60.0)$ & 0.269 \\
\hline Allogenic HSCT recipients & $7(33.3)$ & $30(40.0)$ & 0.763 \\
\hline \multicolumn{4}{|l|}{ Disease status } \\
\hline Active & $17(81.0)$ & $63(84.0)$ & 1.000 \\
\hline Relapsed & $3(14.3)$ & $26(34.7)$ & 0.126 \\
\hline SOFA score & $7.1 \pm 3.6$ & $10.7 \pm 3.9$ & $<0.001$ \\
\hline Charlson Comorbidity Index & $2.0(2.0-3.0)$ & $3.0(2.0-5.0)$ & 0.029 \\
\hline Nosocomial respiratory viral infection & $9(45.0)$ & $43(61.4)$ & 0.291 \\
\hline Presence of pneumonia on ICU admission & $15(71.4)$ & $69(92.0)$ & 0.032 \\
\hline Invasive pulmonary aspergillosis & $1(4.8)$ & $9(12.0)$ & 0.578 \\
\hline \multicolumn{4}{|l|}{ Laboratory findings on ICU admission } \\
\hline Absolute neutrophil count, $\times 10^{9} / \mathrm{L}$ & $2.3(0.6-6.8)$ & $2.5(0.1-6.3)$ & 0.654 \\
\hline Absolute lymphocyte count, $x 10^{9} / \mathrm{L}$ & $0.3(0.1-1.1)$ & $0.5(0.1-1.5)$ & 0.329 \\
\hline Procalcitonin, ng/mL & $\begin{array}{l}2.9(1.0- \\
10.1)\end{array}$ & $1.8(0.9-4.8)$ & 0.472 \\
\hline High sensitivity C-reactive protein, mg/dL & $16.1 \pm 10.2$ & $16.8 \pm 9.2$ & 0.762 \\
\hline \multicolumn{4}{|l|}{ Reasons for ICU admission } \\
\hline Acute respiratory failure & $17(81.0)$ & $68(90.7)$ & 0.397 \\
\hline Sepsis/Septic shock & $14(66.7)$ & $56(74.7)$ & 0.652 \\
\hline \multicolumn{4}{|l|}{ Life-supporting interventions } \\
\hline High flow nasal cannula & $9(42.9)$ & $33(44.0)$ & 1.000 \\
\hline Mechanical ventilation & $6(28.6)$ & $65(86.7)$ & $<0.001$ \\
\hline Renal replacement therapy & $5(23.8)$ & $23(30.7)$ & 0.734 \\
\hline Extracorporeal membrane oxygenation & $0(0.0)$ & $2(2.7)$ & 1.000 \\
\hline
\end{tabular}




\begin{tabular}{|llll|}
\hline Use of medications in 30 days prior to ICU admission & & & \\
Use of corticosteroids & $20(95.2)$ & $64(85.3)$ & 0.401 \\
\hline Accumulative prednisolone-equivalent dose & $10.8(4.2-$ & $12.1(4.2-$ & 0.696 \\
\hline Use of immunosuppressants & $20.0)$ & $21.8)$ & 0.839 \\
\hline Use of anti-cancer chemotherapeutic drugs & $7(33.3)$ & $21(28.0)$ & 0.973 \\
\hline $\begin{array}{l}\text { Other pathogens identified from respiratory } \\
\text { specimens }{ }^{a}(\mathrm{n}=66)\end{array}$ & $15(71.4)$ & $51(68.0)$ & 0.973 \\
\hline Bacteria & $15(71.4)$ & $51(68.0)$ & 0.625 \\
\hline Fungus & $4(26.7)$ & $21(41.2)$ & 1.000 \\
\hline
\end{tabular}

Data are presented as number (percentage) or as median (interquartile range).

PCR, polymerase chain reaction; HSCT, hematopoietic stem cell transplant; SOFA, sequential organ failure assessment score; ICU, intensive care unit

${ }^{a}$ Appropriate sputum specimen was collected from 66 patients.

Table 8

Multivariate analyses with logistic regression models for probability of in-hospital mortality in patients with positive upper airway respiratory virus PCR

\begin{tabular}{|llll|}
\hline Variable & \multicolumn{3}{l|}{ Multivariable } \\
\cline { 2 - 4 } & Adjusted OR & $95 \% \mathrm{Cl}$ & Pvalue \\
\hline Age & 1.01 & $0.99-1.04$ & 0.292 \\
\hline SOFA score & 1.20 & $1.11-1.31$ & $<0.001$ \\
\hline Charlson Comorbidity Index & 1.03 & $0.86-1.24$ & 0.754 \\
\hline Presence of pneumonia at ICU admission & 4.90 & $2.33-10.29$ & $<0.001$ \\
\hline Mechanical ventilation & 6.86 & $3.81-12.36$ & $<0.001$ \\
\hline $\begin{array}{l}\text { PCR, polymerase chain reaction; OR, odds ratio; Cl, confidence interval; SOFA, sequential organ failure } \\
\text { assessment score; ICU, intensive care unit }\end{array}$ & & \\
\hline
\end{tabular}

\section{Discussion}

In this study, we aimed to evaluate the prevalence and impact of RV positivity in the upper airway tract of patients with hematologic malignancies. We found that the rates of in-hospital mortality and ARF was significantly higher among patients with positive than with negative upper airway RV PCR results. 
Furthermore, RV detection in the upper respiratory tract was relatively common among patients with hematologic malignancies and respiratory symptoms who required ICU admission.

In immunocompromised patients with respiratory failure, identification of ARF causes is important to improve the outcomes [26, 27]. Bacterial or fungal infections, including that by Aspergillus and Pneumocystis jirovecii, are usually considered to cause ARF in these patients, while RVs are rarely considered as the cause $[16,19]$. RVs usually cause mild URTIs, but they sometimes cause severe ARF that requires life supporting interventions. Previous studies have reported that RVs are usually found in critically ill patients with pneumonia and associated with ARF and in-hospital mortality $[28,29]$. Although RV PCR is recently used to identify the cause of ARF [30], the clinical relevance of RV detection in upper respiratory tract in critically ill immunocompromised patients, such as those with hematologic malignancies, is still unclear.

In this study, upper respiratory tract RVs were detected in $29.0 \%$ of critically ill patients with hematologic malignancies and respiratory symptoms. This rate is lower than the rates reported in a few previous studies that included immunocompromised patients: 47\% (47/100) among French immunocompromised critically ill patients [19] and 63\% (33/52) among Dutch adult HSCT recipients with respiratory tract illness [18]. However, considering studies using tests on upper respiratory tract samples, our results are consistent with those of a previous multicenter prospective study, in which $26 \%$ of critically ill patients hematologic with malignancy were positive for RVs) [29].

Upper airway tract RV detection was a predictor of ARF, and ICU and in-hospital mortality in the present study. Previous studies have reported the important impact of RV infections on the morbidity and mortality of immunocompromised patients. For example, Fazekas et al. reported that viral URTI in immunocompromised children is associated with high morbidity, particularly among HSCT recipients [31]. Legoff et al. also reported that RV detection in the upper respiratory tract is associated with ARF and higher ICU mortality [29]. The findings of these studies are consistent with those in our study.

In this study, PIV was the most prevalent RV among those detected in the upper airway and was significantly associated with mortality. PIV infection can cause a variety of clinical syndromes, ranging from mild URTI to severe pneumonia [32]. Marcolini et al. previously reported that PIV infection is associated with high rates of pneumonia and mortality, as well as low ALC, in patients with hematologic malignancies [33]. Among immunocompromised patients in our study, HSCT recipients were the most affected by PIV infection. Using viral culture and direct immunofluorescence assay, infection rates of PIV have been shown to range from $2.2 \%$ to $7.1 \%$ among adult HSCT recipients [34-37]. In our study, the prevalence of PIV in allogeneic HSCT recipients was higher (15.4\%) than that previously reported, possibly because of the high sensitivity of the multiplex RV PCR.

Consistently to previous studies, we found that the use and higher dose of corticosteroids are risk factors for positive upper respiratory tract RV detection. This result was the same both for allogenic HSCT recipients and non-HSCT recipients. Systemic steroids have many effects on the innate and acquired immunity, predisposing patients to infection [38, 39]. A previous study also reported that prior treatment 
with corticosteroids or other immunosuppressants increases the risk for viral infection in immunocompromised patients [29]. Furthermore, in allogeneic HSCT recipients, we also found that lymphopenia is a risk factor for positive upper airway tract RV detection. Previous studies about general population have shown that lymphopenia is associated with increased infection rates and infectionrelated deaths $[12,40]$. It has also been reported that lymphopenia is a risk factor for mortality among HSCT recipients with viral infection [41, 42]. It is likely that detection of RVs the in upper airway is associated with a decreased T-cell-mediated immune response after the administration of corticosteroids [43]. These data suggest that clinicians should use corticosteroids more cautiously in patients with hematologic malignancies.

The present study had several limitations. First, this study was not prospective and performed at a single center. Therefore, selection bias may have affected the significance of our findings. However, in this single large, 2-year cohort whose treatment was based on the same protocol, we carefully inspected all patients admitted to the ICU with respiratory symptoms and sampled for upper respiratory tract RV PCR within 24 hours after ICU admission. The aim of this study was to identify the clinical impact of upper airway RV in critically ill patients with hematologic malignancies; thus, the setting of our study did not greatly differ from that of a prospective observational study. Second, lower respiratory tract samples had not been collected for the patients in our study. Therefore, we cannot conclude whether RV positivity reflects true upper or lower respiratory tract infection. Nonetheless, positive nasopharyngeal RV PCR results were significantly associated with in-hospital mortality in this study. A possible explanation for this might be that positive PCR results are a marker for poor immune function in critically ill patients with hematologic malignancies. The presence of viruses in the upper airway may render the host epithelium more susceptible to bacterial colonization, and as a result, promote bacterial pneumonia [44]. Accordingly, previous studies have reported that viral coinfection is associated with a worse prognosis in patients with community-acquired bacterial pneumonia $[45,46]$. Third, our study showed a relatively higher mortality rate (65.9\%) compared to that reported by other studies regarding critically ill patients with hematologic malignancies (43.0\%) [29]. This difference may be explained by the different enrollment criteria. In this study, we enrolled critically ill hematologic malignancy patients with respiratory symptoms, and ARF was the most common reason (81\%) for ICU admission. Moreover, many patients had characteristics associated with poor prognosis, such as relapsed malignancies, which definitely contributed to the high mortality rate.

\section{Conclusion}

We found that RV detection in the upper respiratory tract is relatively common and is significantly associated with poor prognosis in critically ill patients with hematologic malignancies and respiratory symptoms. Among RVs, PIV was more prevalent among patients who died in the hospital. Prior use and higher doses of corticosteroids were associated with positive upper airway RV PCR results. These results indicate that RV detection in the upper respiratory is a predictor of poor prognosis, while patients who have previously received high doses of corticosteroids should be screened for RVs by PCR. Further 
studies including critically ill patients with hematologic malignancies who are positive for RVs in the upper respiratory tract are needed to confirm these results.

\section{List Of Abbreviations}

ADV adenovirus

ALC absolute lymphocyte count

ANC absolute neutrophil count

ARF acute respiratory failure

$\mathrm{CCl} \quad$ Charlson comorbidity score index

$\mathrm{Cl} \quad$ confidence interval

HRV human rhinovirus

hs-CRP high sensitivity C-reactive protein

HSCT hematopoietic stem cell transplantation

ICU intensive care unit

MPV metapneumovirus

OR odds ratio

PIV parainfluenza virus

RSV respiratory syncytial virus

RRT renal replacement therapy

RV respiratory virus

SOFA Sequential Organ Failure Assessment

URTI upper respiratory tract infection

\section{Declarations}

\section{Ethics approval and consent to participate}


The institutional review board of St. Mary's Hospital approved the study. The requirement for informed consent from the patients studied was waived by the ethical review board (KC20RISI0297).

\section{Consent for publication}

No individual participant data is reported that would require consent to publish from the participant.

\section{Availability of data and materials}

The datasets used and/or analysed during the current study are available from the corresponding author on reasonable request.

\section{Competing interests}

The authors declare that they have no competing interests.

\section{Funding}

None

\section{Authors' contributions}

SCK and CKR conceptualized the study design, critically revised the manuscript, and gave final approval of the version to be published. JL (Jaewoong Lee) and JWL conceptualized the study design, contributed to the analysis of the data, and gave final approval of the final version to be published. DGL contributed in the analysis of clinical data, study design and data interpretation, critically reviewed the manuscript, and gave final approval of the final version to be published. $\mathrm{JL}$ (Jongmin Lee) conceptualized the study design, participated in the collection and analysis of the data, wrote the manuscript, critically reviewed the manuscript, and gave final approval of the version to be published.

\section{Acknowledgements}

The authors thank Min Young Park at University of Oregon, for supporting our study.

\section{References}

1. Azoulay E, Mokart D, Pene F, Lambert J, Kouatchet A, Mayaux J, et al. Outcomes of critically ill patients with hematologic malignancies: prospective multicenter data from France and Belgium--a 
groupe de recherche respiratoire en reanimation onco-hematologique study. J Clin Oncol. 2013;31(22):2810-8.

2. Benoit DD, Vandewoude KH, Decruyenaere JM, Hoste EA, Colardyn FA. Outcome and early prognostic indicators in patients with a hematologic malignancy admitted to the intensive care unit for a lifethreatening complication. Crit Care Med. 2003;31(1):104-12.

3. Azoulay E, Schlemmer B. Diagnostic strategy in cancer patients with acute respiratory failure. Intensive Care Med. 2006;32(6):808-22.

4. Bergeron A, Rea D, Levy V, Picard C, Meignin V, Tamburini J, et al. Lung abnormalities after dasatinib treatment for chronic myeloid leukemia: a case series. Am J Respir Crit Care Med. 2007;176(8):814-8.

5. Azoulay E, Canet E, Raffoux E, Lengline E, Lemiale V, Vincent F, et al. Dexamethasone in patients with acute lung injury from acute monocytic leukaemia. Eur Respir J. 2012;39(3):648-53.

6. Rano A, Agusti C, Jimenez P, Angrill J, Benito N, Danes C, et al. Pulmonary infiltrates in non-HIV immunocompromised patients: a diagnostic approach using non-invasive and bronchoscopic procedures. Thorax. 2001;56(5):379-87.

7. Azoulay E, Mokart D, Rabbat A, Pene F, Kouatchet A, Bruneel F, et al. Diagnostic bronchoscopy in hematology and oncology patients with acute respiratory failure: prospective multicenter data. Crit Care Med. 2008;36(1):100-7.

8. Ison MG. Respiratory syncytial virus and other respiratory viruses in the setting of bone marrow transplantation. Curr Opin Oncol. 2009;21(2):171-6.

9. Lee I, Barton TD. Viral respiratory tract infections in transplant patients: epidemiology, recognition and management. Drugs. 2007;67(10):1411-27.

10. Abbas S, Raybould JE, Sastry S, de la Cruz O. Respiratory viruses in transplant recipients: more than just a cold. Clinical syndromes and infection prevention principles. Int J Infect Dis. 2017;62:86-93.

11. Cho SY, Lee HJ, Lee DG. Infectious complications after hematopoietic stem cell transplantation: current status and future perspectives in Korea. Korean J Intern Med. 2018;33(2):256-76.

12. Hong KW, Choi SM, Lee DG, Cho SY, Lee HJ, Choi JK, et al. Lower respiratory tract diseases caused by common respiratory viruses among stem cell transplantation recipients: a single center experience in Korea. Yonsei Med J. 2017;58(2):362-9.

13. Cordey S, Thomas Y, Suter P, Kaiser L. Pilot evaluation of RT-PCR/electrospray ionization mass spectrometry (PLEX-ID/Flu assay) on influenza-positive specimens. Open Virol J. 2012;6:64-7.

14. Hodinka RL. Point: is the era of viral culture over in the clinical microbiology laboratory? J Clin Microbiol. 2013;51(1):2-4.

15. Visseaux B, Collin G, Ichou H, Charpentier C, Bendhafer S, Dumitrescu M, et al. Usefulness of multiplex PCR methods and respiratory viruses' distribution in children below 15 years old according to age, seasons and clinical units in France: A 3 years retrospective study. PLoS One. 2017;12(2):e0172809. 
16. Martino R, Porras RP, Rabella N, Williams JV, Ramila E, Margall N, et al. Prospective study of the incidence, clinical features, and outcome of symptomatic upper and lower respiratory tract infections by respiratory viruses in adult recipients of hematopoietic stem cell transplants for hematologic malignancies. Biol Blood Marrow Transplant. 2005;11(10):781-96.

17. van Elden LJ, van Kraaij MG, Nijhuis M, Hendriksen KA, Dekker AW, Rozenberg-Arska M, et al. Polymerase chain reaction is more sensitive than viral culture and antigen testing for the detection of respiratory viruses in adults with hematological cancer and pneumonia. Clin Infect Dis. 2002;34(2):177-83.

18. van Kraaij MG, van Elden LJ, van Loon AM, Hendriksen KA, Laterveer L, Dekker AW, et al. Frequent detection of respiratory viruses in adult recipients of stem cell transplants with the use of real-time polymerase chain reaction, compared with viral culture. Clin Infect Dis. 2005;40(5):662-9.

19. Schnell D, Legoff J, Mariotte E, Seguin A, Canet E, Lemiale V, et al. Molecular detection of respiratory viruses in immunocopromised ICU patients: incidence and meaning. Respir Med. 2012;106(8):118491.

20. Park JY, Guo W, Al-Hijji M, El Sabbagh A, Begna KH, Habermann TM, et al. Acute coronary syndromes in patients with active hematologic malignancies - Incidence, management, and outcomes. Int $\mathrm{J}$ Cardiol. 2019;275:6-12.

21. Charlson ME, Pompei P, Ales KL, MacKenzie CR. A new method of classifying prognostic comorbidity in longitudinal studies: development and validation. J Chronic Dis. 1987;40(5):373-83.

22. Carratala J, Mykietiuk A, Fernandez-Sabe N, Suarez C, Dorca J, Verdaguer R, et al. Health careassociated pneumonia requiring hospital admission: epidemiology, antibiotic therapy, and clinical outcomes. Arch Intern Med. 2007;167(13):1393-9.

23. Lemiale V, Mokart D, Resche-Rigon M, Pene F, Mayaux J, Faucher E, et al. Effect of noninvasive ventilation vs oxygen therapy on mortality among immunocompromised patients with acute respiratory failure: a randomized clinical trial. JAMA. 2015;314(16):1711-9.

24. Singer M, Deutschman CS, Seymour CW, Shankar-Hari M, Annane D, Bauer M, et al. The Third International Consensus Definitions for Sepsis and Septic Shock (Sepsis-3). JAMA. 2016;315(8):80110.

25. Chemaly RF, Hanmod SS, Rathod DB, Ghantoji SS, Jiang Y, Doshi A, et al. The characteristics and outcomes of parainfluenza virus infections in 200 patients with leukemia or recipients of hematopoietic stem cell transplantation. Blood. 2012;119(12):2738-45; quiz 2969.

26. Azoulay E, Thiery G, Chevret S, Moreau D, Darmon M, Bergeron A, et al. The prognosis of acute respiratory failure in critically ill cancer patients. Medicine (Baltimore). 2004;83(6):360-70.

27. Contejean A, Lemiale V, Resche-Rigon M, Mokart D, Pene F, Kouatchet A, et al. Increased mortality in hematological malignancy patients with acute respiratory failure from undetermined etiology: a Groupe de Recherche en Reanimation Respiratoire en Onco-Hematologique (Grrr-OH) study. Ann Intensive Care. 2016;6(1):102. 
28. Choi SH, Hong SB, Ko GB, Lee Y, Park HJ, Park SY, et al. Viral infection in patients with severe pneumonia requiring intensive care unit admission. Am J Respir Crit Care Med. 2012;186(4):325-32.

29. Legoff J, Zucman N, Lemiale V, Mokart D, Pene F, Lambert J, et al. Clinical significance of upper airway virus detection in critically ill hematology patients. Am J Respir Crit Care Med. 2019;199(4):518-28.

30. Vallieres E, Renaud C. Clinical and economical impact of multiplex respiratory virus assays. Diagn Microbiol Infect Dis. 2013;76(3):255-61.

31. Fazekas T, Eickhoff P, Rauch M, Verdianz M, Attarbaschi A, Dworzak M, et al. Prevalence and clinical course of viral upper respiratory tract infections in immunocompromised pediatric patients with malignancies or after hematopoietic stem cell transplantation. J Pediatr Hematol Oncol. 2012;34(6):442-9.

32. Hall CB. Respiratory syncytial virus and parainfluenza virus. N Engl J Med. 2001;344(25):1917-28.

33. Marcolini JA, Malik S, Suki D, Whimbey E, Bodey GP. Respiratory disease due to parainfluenza virus in adult leukemia patients. Eur J Clin Microbiol Infect Dis. 2003;22(2):79-84.

34. Lewis VA, Champlin R, Englund J, Couch R, Goodrich JM, Rolston K, et al. Respiratory disease due to parainfluenza virus in adult bone marrow transplant recipients. Clin Infect Dis. 1996;23(5):1033-7.

35. Nichols WG, Gooley T, Boeckh M. Community-acquired respiratory syncytial virus and parainfluenza virus infections after hematopoietic stem cell transplantation: the Fred Hutchinson Cancer Research Center experience. Biol Blood Marrow Transplant. 2001;7 Suppl:11S-15S.

36. Elizaga J, Olavarria E, Apperley J, Goldman J, Ward K. Parainfluenza virus 3 infection after stem cell transplant: relevance to outcome of rapid diagnosis and ribavirin treatment. Clin Infect Dis. $2001 ; 32(3): 413-8$.

37. Wendt CH, Weisdorf DJ, Jordan MC, Balfour HH, Jr., Hertz MI. Parainfluenza virus respiratory infection after bone marrow transplantation. N Engl J Med. 1992;326(14):921-6.

38. Strangfeld A, Eveslage M, Schneider M, Bergerhausen HJ, Klopsch T, Zink A, et al. Treatment benefit or survival of the fittest: what drives the time-dependent decrease in serious infection rates under TNF inhibition and what does this imply for the individual patient? Ann Rheum Dis. 2011;70(11):1914-20.

39. Chen JY, Wang LK, Feng PH, Chu CC, Cheng TJ, Weng SF, et al. Risk of shingles in adults with primary Sjogren's syndrome and treatments: a nationwide population-based cohort study. PLoS One. 2015;10(8):e0134930.

40. Warny M, Helby J, Nordestgaard BG, Birgens H, Bojesen SE. Lymphopenia and risk of infection and infection-related death in 98,344 individuals from a prospective Danish population-based study. PLoS Med. 2018;15(11):e1002685.

41. Chemaly RF, Ghosh S, Bodey GP, Rohatgi N, Safdar A, Keating MJ, et al. Respiratory viral infections in adults with hematologic malignancies and human stem cell transplantation recipients: a retrospective study at a major cancer center. Medicine (Baltimore). 2006;85(5):278-87. 
42. Hirsch HH, Martino R, Ward KN, Boeckh M, Einsele H, Ljungman P. Fourth European Conference on Infections in Leukaemia (ECIL-4): guidelines for diagnosis and treatment of human respiratory syncytial virus, parainfluenza virus, metapneumovirus, rhinovirus, and coronavirus. Clin Infect Dis. 2013;56(2):258-66.

43. Nichols WG, Corey L, Gooley T, Davis C, Boeckh M. Parainfluenza virus infections after hematopoietic stem cell transplantation: risk factors, response to antiviral therapy, and effect on transplant outcome. Blood. 2001;98(3):573-8.

44. Bosch AA, Biesbroek G, Trzcinski K, Sanders EA, Bogaert D. Viral and bacterial interactions in the upper respiratory tract. PLoS Pathog. 2013;9(1):e1003057.

45. Cawcutt K, Kalil AC. Pneumonia with bacterial and viral coinfection. Curr Opin Crit Care. 2017;23(5):385-90.

46. Voiriot G, Visseaux B, Cohen J, Nguyen LB, Neuville M, Morbieu C, et al. Viral-bacterial coinfection affects the presentation and alters the prognosis of severe community-acquired pneumonia. Crit Care. 2016;20(1):375.

\section{Figures}

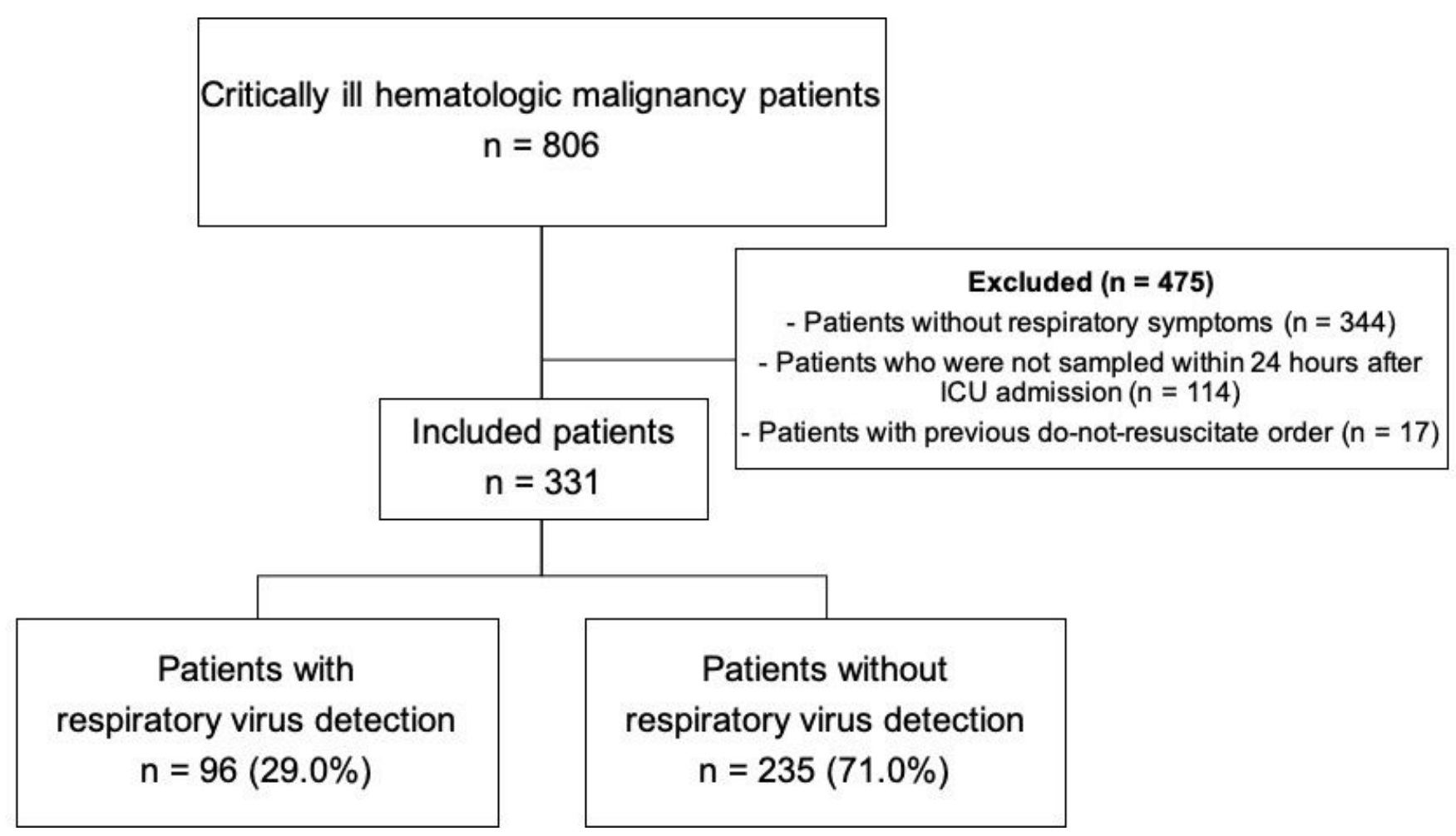

Figure 1

Study flow diagram. ICU, intensive care unit 


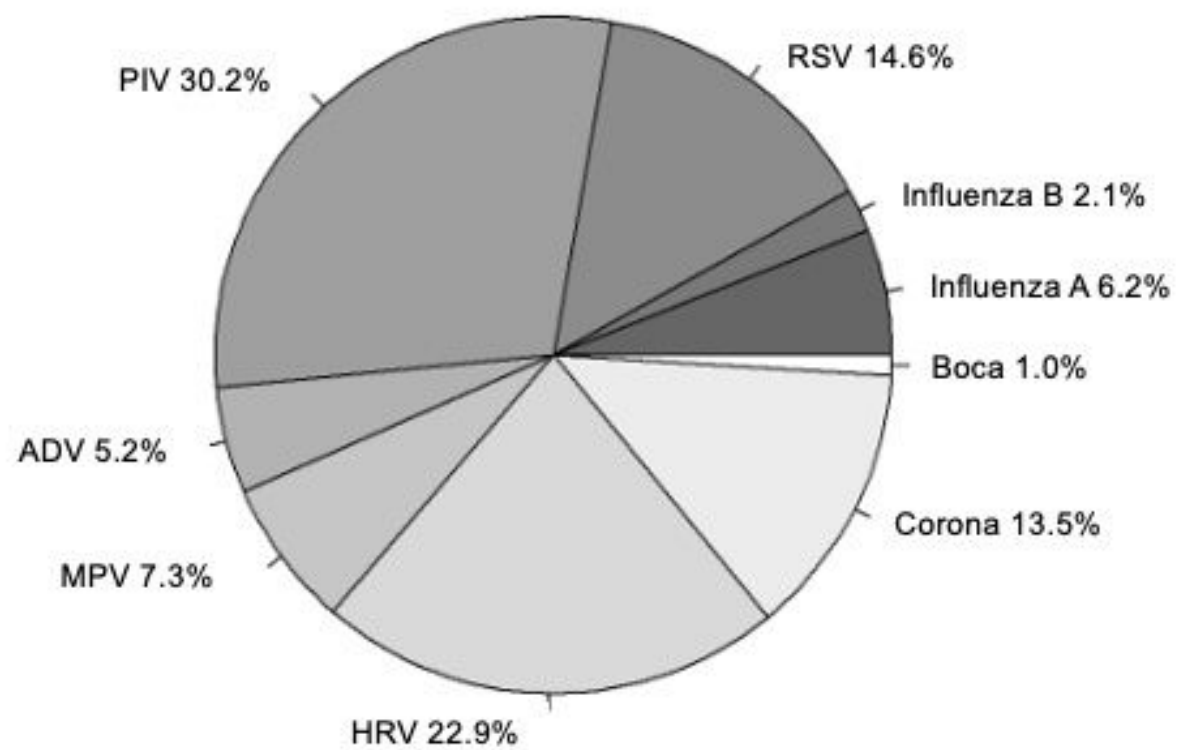

Figure 2

Patients' distribution according to the type of upper airway respiratory virus detected in nasopharyngeal samples by PCR. PIV, parainfluenza virus; RSV, respiratory syncytial virus; Boca, bocavirus; Corona, coronavirus; HRV, rhinovirus; MPV, metapneumovirus; ADV, adenovirus

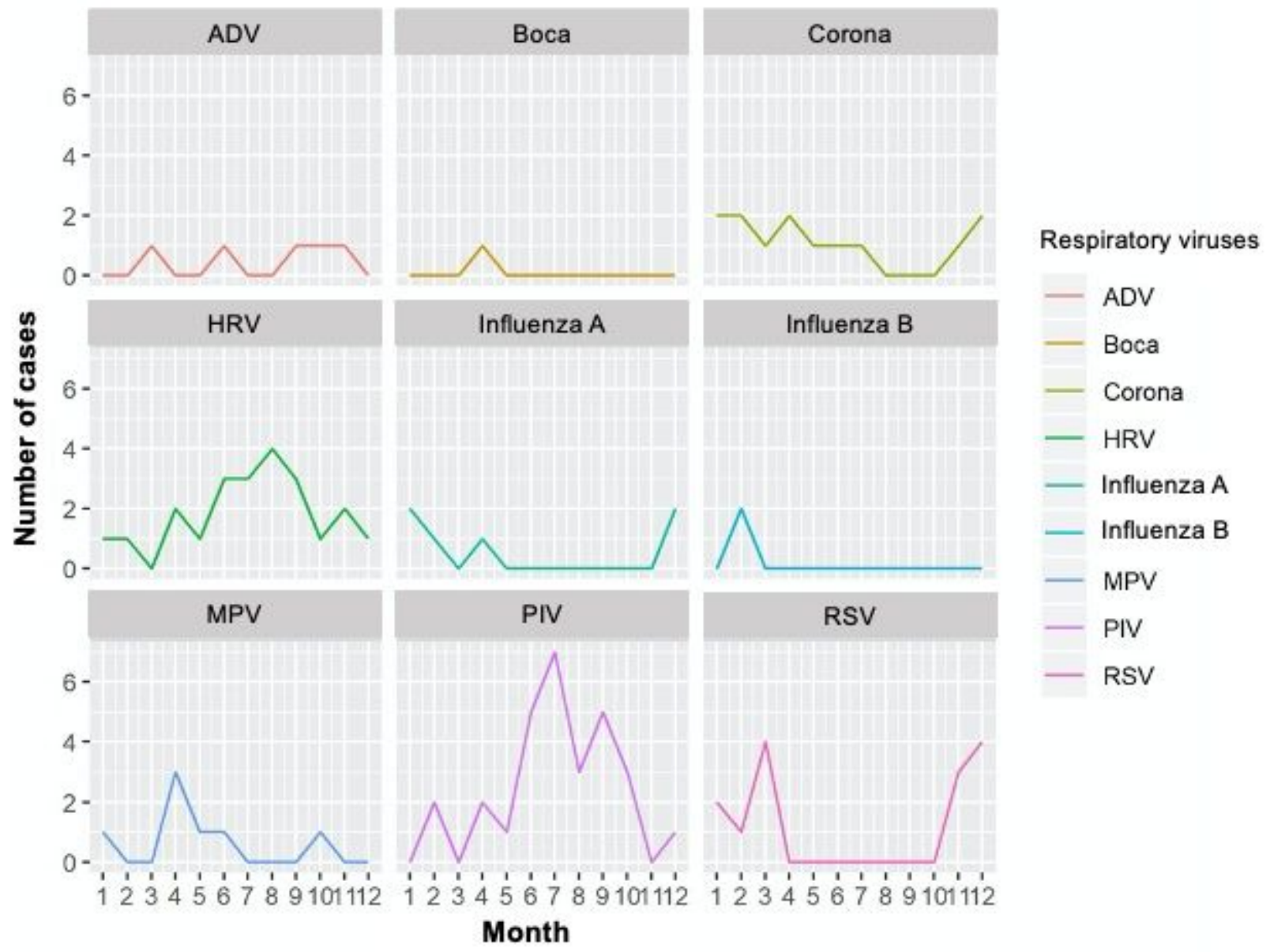




\section{Figure 3}

Monthly distribution of upper airway respiratory virus detection cases. PIV, parainfluenza virus; RSV, respiratory syncytial virus; Boca, bocavirus; Corona, coronavirus; HRV, rhinovirus; MPV, metapneumovirus; ADV, adenovirus.

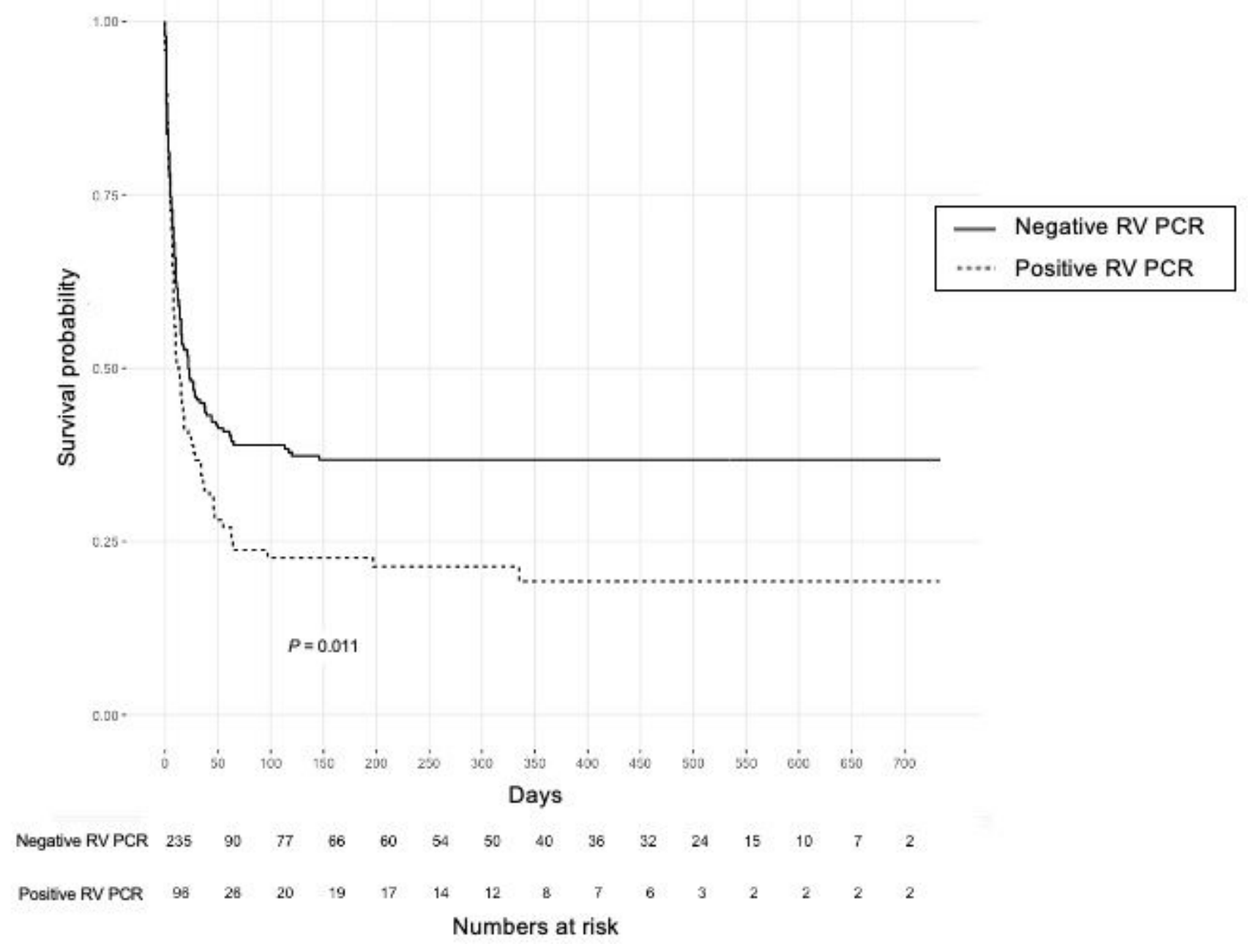

\section{Figure 4}

Kaplan-Meier curves of the probability of survival in patients with upper airway respiratory virus (positive RV PCR group, dotted line) and those without (negative RV PCR group, solid line). RV, respiratory virus.

\section{Supplementary Files}

This is a list of supplementary files associated with this preprint. Click to download.

- AdditionalTables.docx 